\title{
Stability indicating RP-HPLC method development and validation of cefepime and amikacin in pure and pharmaceutical dosage forms
}

\author{
Lella Kalyani', Chava Venkata Nageswara Rao ${ }^{2 *}$
}

\author{
${ }^{1}$ Department of Chemistry, NRI Institute of Technology, Perecherla, Guntur Dt., AP, India, ${ }^{2}$ Department of Chemistry, NRI \\ Institute of Technology, Pothavarappadu, Agiripalli Mandal,Krishna dt., AP, India
}

\begin{abstract}
A simple, accurate, isocratic stability indicating RP-HPLC method was developed for the determination of cefepime and amikacin in Pure and its pharmaceutical formulations. The method consists of methanol: acetonitrile:acetate buffer 75:20:05 (v/v) mobile phase at pH 5.1 with $\mathrm{C} 18$ column as stationary phase. The flow rate and detection wave length were $1.0 \mathrm{~mL} / \mathrm{min}$ and $212 \mathrm{~nm}$ respectively. The linearity range for the method was found to be $2.5-25 \mu \mathrm{g} / \mathrm{mL}$ for amikacin and $10-100 \mu \mathrm{g} / \mathrm{mL}$ cefepime respectively. The developed method was validated as per ICH guidelines and the results of all the validation parameters were well within their acceptance values. Also the forced degradation studies were conducted with standard drugs. Degradation products formed during the different stress conditions were separated from both drugs. This validated method was applied for the simultaneous estimation of cefepime and amikacin in commercially available formulation sample.
\end{abstract}

Keywords: Cefepime/method development and validation. Amikacin/method development and validation. RP-HPLC.

\section{INTRODUCTION}

Cefepime is a broad-spectrum cephalosporin antibiotic with greater activity against both gram-negative and gram-positive organisms than third-generation agents (Ahavet al., 2007; Chapman, Perry, 2003). Chemical name of the cefepime is $(6 R, 7 R)-7-[[(2 Z)-2-(2$-amino1,3-thiazol-4-yl)-2-methoxyiminoacetyl]amino]-3-[(1methyl pyrrolidin-1-ium-1-yl) methyl]-8-oxo-5-thia-1azabicyclo[4.2.0] oct-2-ene-2-carboxylate - Figure 1a (http://www.chemspider.com). It is a fourth-generation antibiotic used for treatment of pneumonia (moderate to severe) caused by Streptococcus pneumoniae, including cases associated with concurrent bacteremia, Pseudomonas aeruginosa, Klebsiella pneumoniae, or Enterobacter species. Also for empiric treatment of febrile neutropenic patients and uncomplicated and complicated urinary tract infections (including pyelonephritis), uncomplicated skin and skin structure infections, complicated intra-abdominal

\footnotetext{
*Correspondence: C. V. N. Rao. Department of Chemistry, NRI Institute of Technology, Pothavarappadu, AgiripalliMandal, Krishna dt., AP, India, 521212. E-mail: chavavnrao@gmail.com
}

infections (used in combination with metronidazole) caused by different bacterial species.

Amikacin is an aminoglycoside antibiotic used for treatment of different types of bacterial infections. Chemical name of the amikacin is $(2 S)$-4-amino- $N$ $[(1 R, 2 S, 3 S, 4 R, 5 S)-5$-amino-2-[(2S,3R,4S,5S,6R)-4amino-3,5-dihydroxy-6-(hydroxyl methyl)oxan-2-yl] oxy-4-[(2R,3R,4S,5S,6R)-6-(aminomethyl)-3,4,5trihydroxyoxan-2-yl]oxy-3-hydroxycyclohexyl]2-hydroxybutanamide - Figure 1b (ChemicalStructure.34635.htmL). It is a semi-synthetic drug derived from kanamycin A with multidrug-resistant Gram-negative bacteria such as Pseudomonas aeruginosa, Acinetobacter, and Enterobacter (Grassi, Grassi, 1993; Tally et al., 1975; Brewer, 1977). Serratia marcescens and Providencia stuartii are also included in the spectrum. It can also be used to treat non-tubercular mycobacterial infections and tuberculosis (if caused by sensitive strains) when first-line drugs fail to control the infection (Pickering, Rutherford, 1981; WHO, 2013). Amikacin may be combined with a beta-lactam antibiotic for empiric therapy for people with neutropenia and fever. It works by disrupts bacterial protein synthesis by binding to the $30 \mathrm{~S}$ ribosome of 


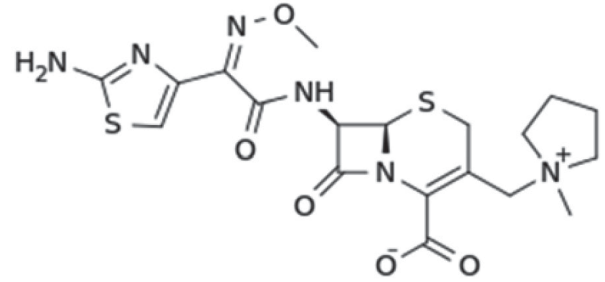

(a)

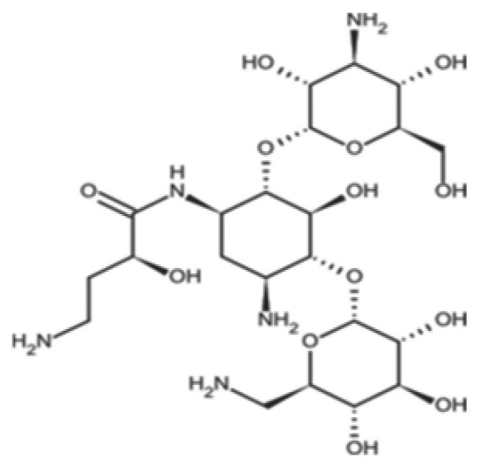

(b)

FIGURE 1 - Chemical structure of cefepime (a) and amikacin (b)

susceptible organisms similar to other aminoglycosides (Pickering, Rutherford, 1981).

Various methods have been reported for analysis of cefepime (Spectrophotometry: Rambabu, Jyothirmayee, Naga Raju, 2012; Elazazy, Shalaby, 2012; Khare et al., 2012; Sujith, Abraham, Divakar, 2010; Nanda et al., 2012; Chafle, 2013; El-Shanawany et al., 2014; Patel et al., 2015a; Papanna, Krishnegowda, Nagaraja, 2015; Kant et al., 2015; Bhupendra, Bhuyan, Sinha, 2011; Chromatography: Sunitha et al., 2013; Dave Vimal, 2012; Patil et al., 2012; Khan, Iqbal, Khattak, 2012; Medina et al., 2007; Patel et al. 2010; Panchal Vipul et al., 2014; Ashok, Veenaeesh, Siripurapu, 2013; Syama Sundar, Gurucharana Das, 2014; Bhavana et al., 2013; AbdelAziz et al., 2014; Mughal et al., 2016; Chromatography: Sunitha et al., 2013; Dave Vimal, 2012; Patil et al., 2012; Ramakrishna et al., 2014; Behan, Punitha, Krishanan, 2013; Khan, Iqbal, Khattak, 2012; Medina et al., 2007; Patel et al., 2010; Neelima et al., 2013;Patel et al., 2015b; Baririan et al., 2003; Panchal Vipul et al., 2014; Ashok et al., 2013; Syamsundar, Guruchana Das, 2014; Arayne, Sulthana, Nawaz, 2006; Bhavana et al., 2013; Trivedi, Kshtri, Patel, 2013; Abdel-Aziz et al., 2014) and along with other combination of drugs and few analytical methods have been reported with the amikacin drug (Spectrophotometry: Mugal et al., 2016; Omar et al., 2013; Soltés, 1999, Omara, Amin, 2013; Ryan, 1984; Chromatography: Feng, et al., 2001; Mokh et al., 2014; Isoherranen, Soback, 1999; Bhatt et al., 2015). But there is only one spectrophotometry method reported for the analysis of both cefepime and amikacin in combination (Kalyani, Rao, 2016). So the present work is aimed to develop the HPLC methods for estimation of cefepime and amikacin in combination. Hence the present work focuses in developing the RP-HPLC methods for the estimation of cefepime and amikacin in combined dosage forms.

\section{EXPERIMENTAL}

\section{Chemicals and materials}

Analytically pure cefepime and amikacin were obtained as gift sample from reputed Pharmaceutical companies. Methanol, acetonitrile, water (Merck, Mumbai, India) were of HPLC grade, while Acetate Buffer used for the preparation of mobile phase was of analytical grade (Merck Specialties Private Limited, Mumbai, India). The membrane filters $0.22 \mu \mathrm{m}$ and syringe filters $0.45 \mu \mathrm{m}$ for the analysis were supplied by Millipores ${ }^{\circledR}$ (Millipores Ltd. Banglore). Formulations of Potentox (Injection vials) contains a combination of cefepime and amikacin containing labeled amount of cefepime - $500 \mathrm{mg}$ and amikacin - $125 \mathrm{mg}$ were procured from local market.

\section{Equipment}

The Liquid Chromatographic procedures were carried out on PEAK chromatographic system make HPLC, equipped with LC-P7000 binary gradient pumps, with variable wavelength programmable UV7000 detector and diode array detector. Rheodyne injector with $20 \mu \mathrm{L}$ fixed loop was used for sample injection. Chromatographic integration and processing were carried out on PEAK Chromatographic Software version 1.06. Waters XTerra ${ }^{\circledR}$ RP- C-18 (250 mm x $4.6 \mathrm{~mm}, 5 \mu \mathrm{m})$ column is used as stationary phase for separation. Standard and sample drugs were weighed by using Denver electronic analytical balance (SI-234).

\section{Preparation of mobile phase}

The mobile phase was prepared by mixing methanol: acetonitrile:acetate buffer 75:20 (v/v) ratio and 5\% of acetate buffer was added to adjust the $\mathrm{pH}$ at 5.1. Mobile 
phase was sonicated for $15 \mathrm{~min}$ and before use the mobile phase was filtered through $0.22 \mu \mathrm{m}$ membrane filter.

\section{Preparation of standard solutions}

A stock solution of cefepime and amikacin was prepared by dissolving $100 \mathrm{mg}$ of the drug in $100 \mathrm{~mL}$ volumetric flask with methanol individually. Aliquots of this solution were suitably diluted with mobile phase to get working standard solutions of cefepime and amikacin in the concentration range of $2.5-25 \mu \mathrm{g} / \mathrm{mL}$ for amikacin and $10-100 \mu \mathrm{g} / \mathrm{mL}$ for cefepime.

\section{Preparation of sample solution for assay}

Ten vial (injection) formulations of Potentox consisting cefepime - $500 \mathrm{mg}$ and amikacin - $125 \mathrm{mg}$ were soaked in $5 \mathrm{~mL}$ diluents and were kept it for solubility for $1 \mathrm{~h}$. Then it was filtered to make up to $10 \mathrm{~mL}$ with same diluents to make $100 \mu \mathrm{g} / \mathrm{mL}$ stock solutions. From this by proper dilution a concentration of $30 \mu \mathrm{g} / \mathrm{mL}$ of cefepime and $7.50 \mu \mathrm{g} / \mathrm{mL}$ amikacin were prepared according to its label claim. The resultant solution was used for the simultaneous estimation of cefepime and amikacin in combined dosage forms.

\section{Forced degradation studies}

To perform the forced degradation study $50 \mathrm{mg}$ drug was subjected to acidic, alkaline, oxidizing, thermal and photolytic conditions. For acidic degradation the drug was heated under reflux with $0.1 \mathrm{M} \mathrm{HCl}$ at $80{ }^{\circ} \mathrm{C}$ for $2 \mathrm{~h}$ and the mixture was neutralized. For alkaline degradation the drug was treated with $0.1 \mathrm{M} \mathrm{NaOH}$ at $80^{\circ} \mathrm{C}$ for $2 \mathrm{~h}$ and the mixture was neutralized. For degradation under oxidizing conditions the drug was heated under reflux with $(30 \%, v / v) \mathrm{H}_{2} \mathrm{O}_{2}$ at $80^{\circ} \mathrm{C}$ for $2 \mathrm{~h}$. For thermal degradation the powdered drug was exposed at $70{ }^{\circ} \mathrm{C}$ for $48 \mathrm{~h}$. For photolytic degradation the powdered drug was exposed to sunlight for $48 \mathrm{~h}$. The placebo was also subjected to the same stress conditions to determine whether any peaks arose from the declared excipients. After completion of the treatments the solutions were left to return to room temperature and diluted with solvent mixture to furnish $30 \mu \mathrm{g} / \mathrm{mL}$ concentrated solutions. The purity of the drug peak obtained from the stressed sample was measured by UV detector and compares the chromatogram of untreated drugs in tablet solution.

\section{RESULTS AND DISCUSSION}

\section{Method development}

After optimizing several conditions for determination of cefepime and amikacin mobile phase consisting of Methanol: Acetonitrile: Acetate Buffer 75:20:05 $(\mathrm{v} / \mathrm{v})$ at $\mathrm{pH} 5.1$ was found to be satisfactory. The drugs gave symmetric and sharp peaks with Waters C-18 $(250 \mathrm{~mm} \times 4.6 \mathrm{~mm}, 5 \mu \mathrm{m})$ column at $212 \mathrm{~nm}$ UV detector. The elution was achieved at $4.61 \mathrm{~min}$ for amikacin and $9.09 \mathrm{~min}$ for cefepime with good resolution, theoretical plates and acceptable tailing factor (Figure 2).

\section{HPLC Report}

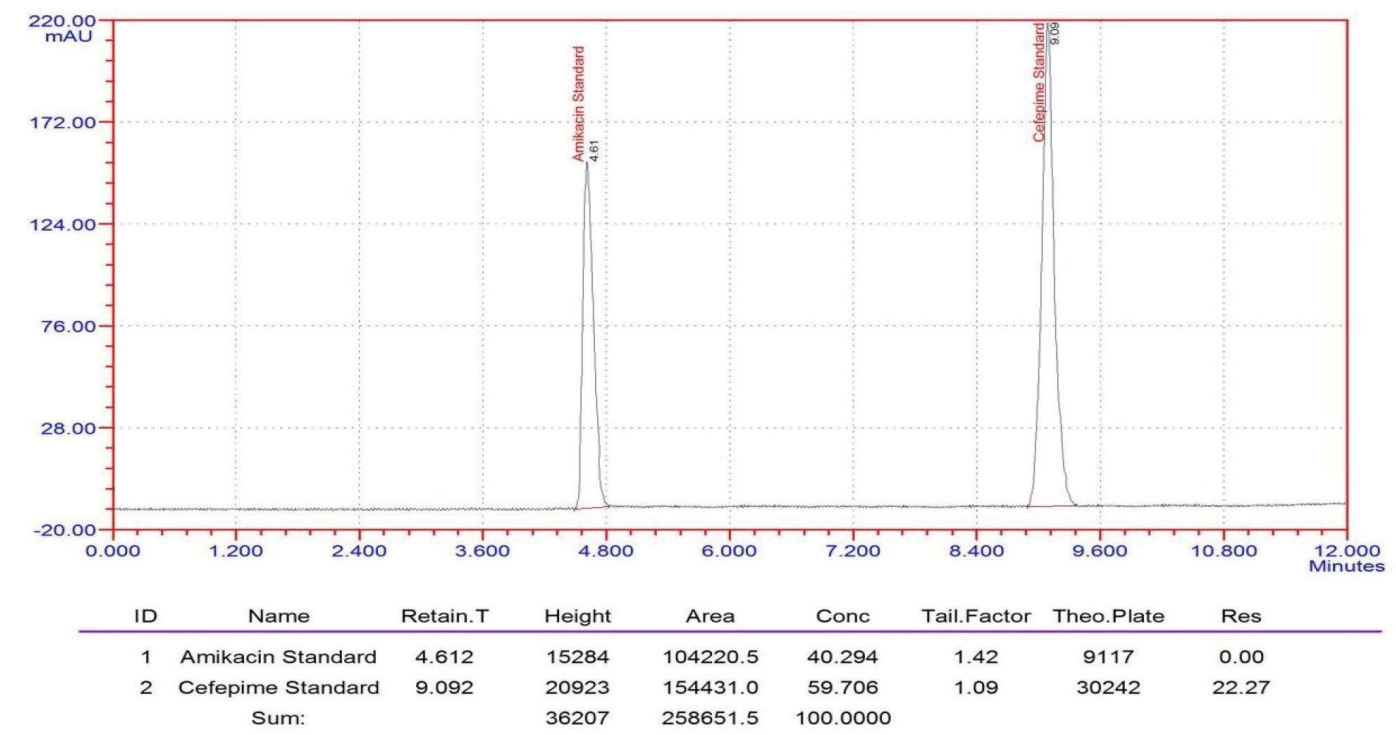

FIGURE 2 - Standard chromatogram of cefepime and amikacin 


\section{Method validation}

The method system suitability was evaluated by calculating the \%RSD values of peak area, retention time, asymmetry and theoretical plates of five standard replicates. The experimental results (Table I) showed that the values were within the acceptable range indicating that the system was suitable for the intended analysis. Specificity results indicate that there was no interference from the excipients used and also from the mobile phase which proves that method is able to separate the main drugs from the degradation products. The specificity determined by using peak purity, resolution. Peak purity index shows that both cefepime and amikacin are clearly separated from the response of any interfering peak(s). Thus specificity study ensures the selectivity of the developed analytical method which is able to separate and quantify cefepime and amikacin in presence of different degradation products. Range of linearity of the proposed method was determined at different concentrations ranging from $2.5-25 \mu \mathrm{g} / \mathrm{mL}$ for amikacin and $10-100 \mu \mathrm{g} / \mathrm{mL}$ for cefepime. The regression analysis equation was $\mathrm{y}=8916 . \mathrm{x}+36284$ and correlation coefficient $\left(\mathrm{r}^{2}\right)$ was 0.999 for amikacin and $y=4442 . x+20680$ and correlation coefficient $\left(\mathrm{r}^{2}\right)$ was 0.999 for cefepime. Very low values for the statistical parameters like standard deviation of slope, intercept 102.80, 1594.67 for amikacin and $33.79,2093.93$ for cefepime indicate that there is linear relationship between the concentration and peak area. A very low standard deviation in quantitative analysis results 0.2505 for amikacin and 0.5906 for cefepime indicates that the quantity reported is accurate and acceptable. Hence the quantity of amikacin and cefepime can be accurately determined using the calibration graphs which were represented in Figure 3.

Other key parameters like precision, ruggedness and robustness results are also within the limit. For amikacin $\% \mathrm{RSD}$ is found to be $1.39,0.17$ and 1.363 for intraday,

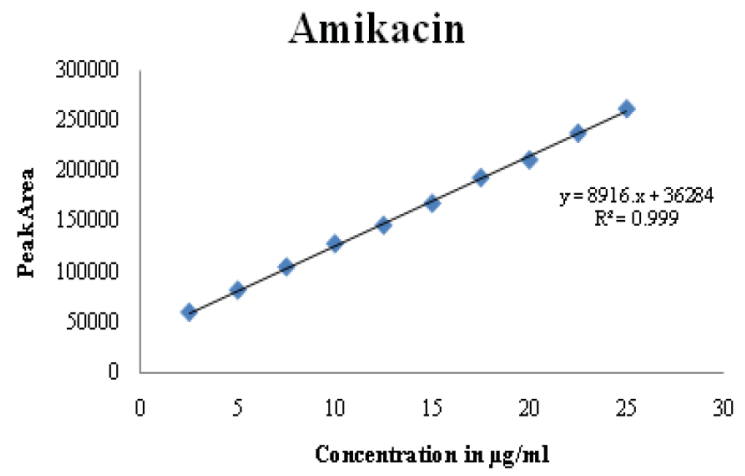

TABLE I - System suitability test results

\begin{tabular}{ll}
\hline Parameter & Results \\
\hline API Concentration & $\begin{array}{l}\text { Amikacin }-7.5 \mu \mathrm{g} / \mathrm{mL} \\
\text { Cefepime }-30 \mu \mathrm{g} / \mathrm{mL}\end{array}$ \\
RT & Amikacin $-4.61 \pm 0.0032 \mathrm{~min}$ \\
& Cefepime- $9.09 \pm 0.054 \mathrm{~min}$ \\
Resolution & Amikacin- $\ldots \ldots$. \\
& Cefepime $-22.27 \pm 0.31$ \\
Area & Amikacin $-104220 \pm 630$ \\
& Cefepime- $154431 \pm 595$ \\
TheoreticalPlates & Amikacin- $9117 \pm 125$ \\
& Cefepime- $30242 \pm 240$ \\
TailingFactor & Amikacin- $1.42 \pm 0.01$ \\
& Cefepime- $1.09 \pm 0.01$ \\
\hline
\end{tabular}

inter day and ruggedness studies. And \% RSD of cefepime is found to be $0.51,0.58$ and 0.86 intraday, inter day and ruggedness respectively. Mean recovery $99.31 \%, 98.82 \%$ and $101.56 \%$ for amikacin and $100.53 \%, 100.44 \%$, and $101.19 \%$ for cefepime reveal that the intraday precision, inter day precision and ruggedness are in acceptable limit and hence is reliable. Accuracy of the method was studied by applying the developed method to the prepared synthetic mixtures of formulation excipients to which known amount of cefepime and amikacin were added. Mean recovery for amikacin was between 98.3$100.37 \%$ and $98.58-101.37 \%$ for cefepime indicating the accuracy of the developed method. The percentage of change in results for robustness study includes $0.1-1.4 \%$ for amikacin and $0.14-0.89 \%$ for cefepime respectively. LOD value was found to be $0.003 \mu \mathrm{g} / \mathrm{mL}$ and LOQ was $0.01 \mu \mathrm{g} / \mathrm{mL}$ for amikacin and $0.05 \mu \mathrm{g} / \mathrm{mL}$ and LOQ was $0.20 \mu \mathrm{g} / \mathrm{mL}$ for cefepime respectively.

When compared with literature data reported with methods of cefepime and amikacin, it was found that no RP-HPLC method was reported for forced degradation

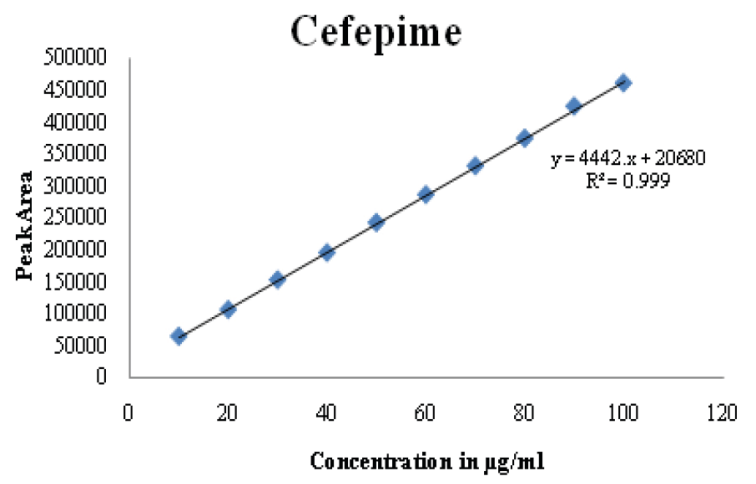

FIGURE 3 - Calibration graph of linearity of cefepime and amikacin 
studies. Dave Vimal described the RP-HPLC Method for Simultaneous Estimation of Cefepime Hydrochloride and Amikacin Sulfate in Injection Dosage Form (Dave Vimal, 2012).A statistical comparison of the quantitative determination of cefepime and amikacin shows that HPLC method is more accurate and precise than UV method (Bhatt et al., 2015). Hence the proposed method was found to be novel for stability indicating study of cefepime and amikacin as well as simultaneous estimation in formulation dosage form.

The solution stability of the standard and the test sample solution were checked by analyzing both the solutions at interval of $12 \mathrm{~h}$ till $24 \mathrm{~h}$ at room temperature.
The results showed that both the retention time and area of both the drugs were unchanged and no significant degradation was observed within the indicated period which was sufficient for performing analytical process. There is good percentage of recovery when combined dosage form Potentox formulation was analyzed. In these results about $99.16 \%$ of assay for amikacin and $99.20 \%$ of assay for cefepime was found.

The proposed validated liquid chromatographic method was successfully applied to study the stress degradation property of cefepime and amikacin. The results of forced degradation studies are given in Table II and Figure4. Results indicate that this method is able to
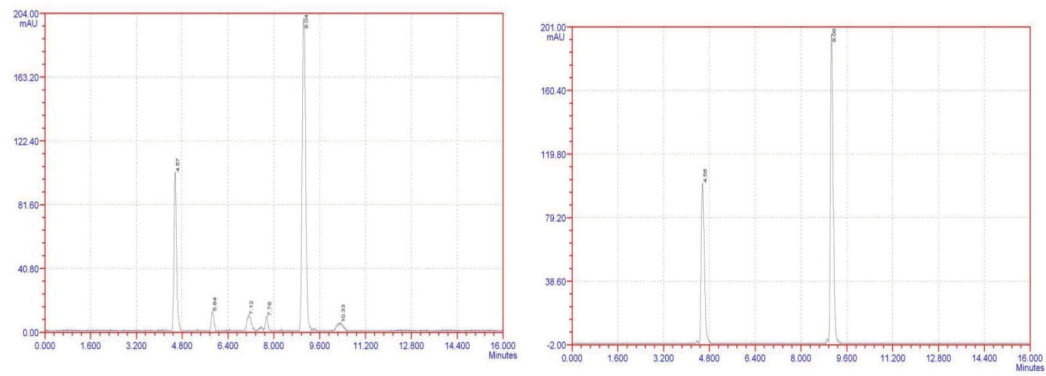

Acidic

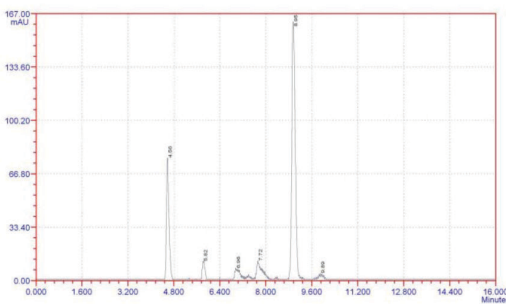

Aqueous

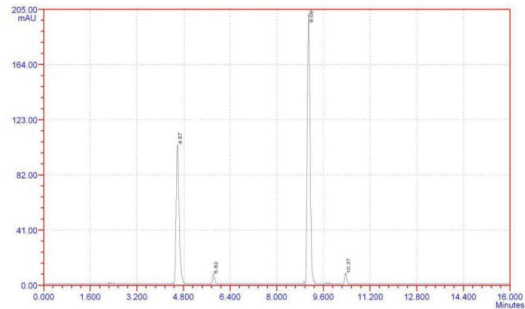

Alkali

Thermal

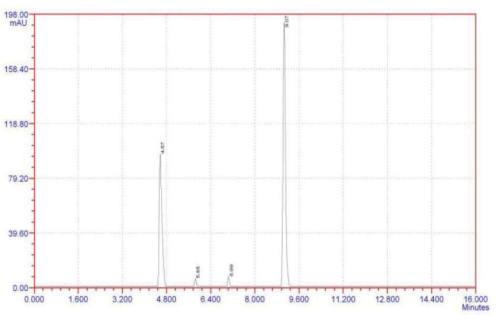

Sunlight

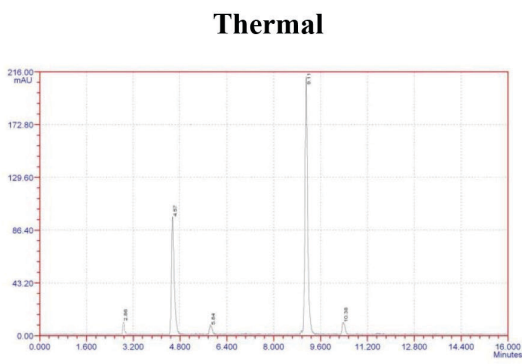

Peroxide

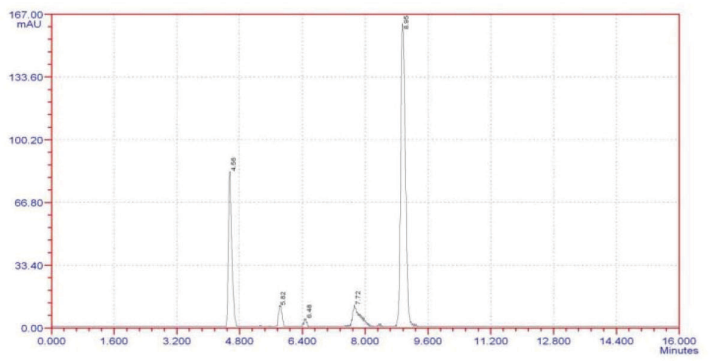

UV light

FIGURE 4 - Forced degradation chromatograms of cefepime and amikacin 
TABLE II - Forced degradation study results

\begin{tabular}{lcccccc}
\hline \multirow{2}{*}{ S. No } & \multirow{2}{*}{ Condition } & $\begin{array}{c}\text { Number of } \\
\text { additional peaks }\end{array}$ & \multicolumn{2}{c}{ Amikacin } & \multicolumn{2}{c}{ Cefepime } \\
\hline 1 & Acidic & 4 & 96.8682 & 3.13184 & 97.0058 & 2.99422 \\
2 & Aqueous & $\ldots$ & 100.13 & $\ldots$ & 97.2266 & 2.77341 \\
3 & Base & 4 & 88.1126 & 11.8874 & 92.2237 & 7.77629 \\
4 & Heat & 2 & 98.9513 & 1.04874 & 95.2937 & 4.70631 \\
5 & Light & 2 & 98.2585 & 1.74151 & 98.4032 & 1.59683 \\
6 & Peroxide & 3 & 97.5389 & 2.46114 & 98.003 & 1.99701 \\
7 & UV & 3 & 99.9808 & 0.01919 & 93.2798 & 6.72015 \\
\hline
\end{tabular}

TABLE III - Comparison between the proposed and the reported methods for the determination of the studied amikacin and cefepime in pharmaceutical dosage form

\begin{tabular}{lcccc}
\hline \multirow{2}{*}{ Pharmaceuticaldosageform } & \multicolumn{2}{c}{ \% Recovery \pm SD $^{*}$} & \multirow{2}{*}{ F- value } & \multirow{2}{*}{ t-value } \\
\cline { 2 - 3 } & Proposedmethod & Reportedmethod & & \\
\hline Amikacin 125mg vials & $99.13 \pm 1.026$ & $99.16 \pm 0.69$ & 2.204 & 0.053 \\
Cefepime 500mg vials & $99.93 \pm 0.17$ & $99.19 \pm 0.59$ & 12.00 & 6.220 \\
\hline
\end{tabular}

* Averageoffivedeterminations. Tabulated value at $95 \%$ confidence limits are $\mathrm{F}=6.39, \mathrm{t}=2.132$. Tabulated value at $99 \%$ confidence limit is $\mathrm{F}=16$. Tabulated value at $99.9 \%$ confidence limit is $\mathrm{t}=7.173$.

separate successfully and the degradation products are identified. The results reveal that drugs are sensitive to acidic and alkali conditions where more degradation occurred and stable in aqueous condition where there is no degradation observed.

\section{Application to pharmaceutical dosage form}

The proposed method was applied for determination of drugs in the commercial pharmaceutical dosage forms. The results are statistically compared with those of reported methods (Omar et al., 2012, Chafle, 2013) with respect to accuracy and precision. The obtained mean recovery values are $99.16 \pm 0.69$ and $99.19 \pm 0.59$ for amikacin and cefepime respectively, as shown in Table III. F and t-tests are performed on this data and no significant difference was found between the calculated and theoretical values of both the proposed and the reported methods at 95\%, 99\% and $99.9 \%$ confidence level. This indicates good level of precision and accuracy.

\section{CONCLUSION}

The developed method is simple, sensitive, accurate and precise. The proposed method is specific for determination of cefepime and amikacin in pure and as well as formulation analysis. The method was successfully used for determination of cefepime and amikacin in its pharmaceutical formulations and good recovery was found. As the method separates the drug from its degradation products, the method can be conveniently used for routine quality control analysis of cefepime and amikacin in industries for batch release.

\section{REFERENCES}

Abdel-Aziz O, Farouk M, Nagi R, Abdel-Fattah L. Simple chromatographic methods for determination of cefepime in bulk powder and injection dosage form, and in presence of its hydrolytic degradation products. Anal Chem Indian J. 2014;14(7):274-281.

Ahav D, Paul M, Fraser A, Sarid N, Leibovici L. Efficacy and safety of cefepime: a systematic review and meta-analysis. Lancet Infect Dis. 2007;7(5):338-48.

Arayne MS, Sultana N, Nawaz M.A RP-HPLC method for the assay of cefpirome and its application in drug-metal interaction studies.Pak J Pharm Sci. 2006;19(1):38-43. 
Ashok M, Veenaeesh K, Siripurapu MKG. Simultaneous estimation of cefepime $\mathrm{HCl}$ and tazobactam sodium in injection dosage form by using RP-HPLC. Int J Pharm Biosci. 2013,3(4):188-192.

Baririan N, Chanteux H, Viaene E, Servais H, Tulkens PM.Stability and compatibility study of cefepime in comparison with ceftazidime for potential administration by continuous infusion under conditions pertinent to ambulatory treatment of cystic fibrosis patients and to administration in intensive care units. J Antimicrob Chemother. 2003; 51(3):651-658.

Behan S, Punita ISR, Krishnan S. Stability studies of cefepime hydrochloride by stability indicating RP-HPLC method.Int J Pharm SciNanotechnol. 2013;6(3):895-901.

Bhatt DA, Prajapati LM, Joshi AK, Lkharodiya M. Development and validation of spectrophotometry method for simultaneous estimation of cefepime hydrochloride and amikacin sulphate. World JPharm Res. 2015;4(5):1482-1491.

Bhavana M, Ramamohana Reddy T, Sandhya M, Rao UMV. RP-HPLC method development and validation for simultaneous estimation of cefepime and tazobactam in marketed formulation. Int J Pharm. 2013;3(4):837-842.

Bhupendra S, Bhuyan NR, Sinha BN. Analysis of two cephalosporin drugs ceftriaxone and cefepime alone and in presence of two $\beta$-lactamase inhibitors sulbactam and tazobactam, Asian J Chem. 2011;23(11):4751-4756.

Brewer NS. Antimicrobial agents - part II. The aminoglycosides streptomycin, kanamycin, gentamicin, tobramycin, amikacin, neomycin.Mayo Clin Proc. 1977;52(11):675-9.

Chafle DM. Development and validation of spectrophotometric method for the estimation of cefepime in bulk and dosage form. Der Pharma Chemica. 2013;5(2):127-132.

Chapman TM, Perry CM. Cefepime: A review of its use in the management of hospitalized patients with pneumonia. Am J Respir Med. 2003;2(1):75-107.

Chemspider.Amikacin. Available from: http://www.chemspider. com/Chemical-Structure.34635.htmL.

Chemspider.Cefepime. Available from: http://www.chemspider. com/Chemical-Structure.4586395.htmL.
Dave Vimal M. Development and validation of RP-HPLC method for simultaneous estimation of cefepime hydrochloride and amikacin sulphate in injection dosage form. J Pharm Sci Bioscient Res. 2012;2(3):138-143.

Elazazy MS, Shalaby AA. Validated spectrophotometric assay of cefepime hydrochloride and cefuroxime sodium using a tetrazolium salt. E-J Chem.2012;9(4):2261-2267.

El-Shanawany AA, El-Adl SM, Abdel-Aziz LM, Hassan AF.Bromatometric estimation of cefepime, cefoperazone, and cefotriaxone in their bulk and dosage forms. Asian J Pharm Anal. 2014;4(1):17-27.

Feng CH, Lin SJ, Wu HL, Chen SH. Trace analysis of amikacin in human plasma by high-performance liquid chromatography. Chromatographia. 2001;53 (Suppl 1):S213-S217.

Grassi GG, Grassi C. Cefepime: overview of activity in vitro and in vivo. J Antimicrob Chemother. 1993;32 (SupplB):87-94.

Isoherranen N, Soback S. Chromatographic methods for analysis of aminoglycoside antibiotics. J AOAC Int. 1999;82(5):1017-45.

Kalyani L, RAO CVN. Spectrophotometric methods for the simultaneous estimation of amikacin and cefepime in pharmaceutical formulations. Eur J Biomed Pharm Sci. 2016;3(12):331-338.

Kant R, Bodla R, Bhutani R, Kapoor G, Goswami S. Spectrophotometric absorbance correction method for the estimation of Tazobactam and cefepime in combined tablet dosage forms. J Chem Pharm Res. 2015;7(6):648-656.

Khan AU, Iqbal J, Khattak S-U-R. Kinetics of degradation of cefepime hydrochloride in various aqueous based solutions. Int J Pharm Tech. 2012;4(1):4079-89.

Khare NK, Nanda RK, Lawrence RM, Navathar DA. Development and validation of spectrophotometric methods for simultaneous estimation of cefepime and tazobactam in combined dosage form by area under curve and q-analysis. Int J Institut Pharm Life Sci.2012;2(2):1-8

Medina ELR, Mejia SR, Romero MDCM, Milan RCS, Romano SM. Micro method for the determination of cefepime by high performance liquid chromatography, El Trabajo Científico. 2007;38(1):34-41. 
Mokh S, Jaber F, Kouzayha A, Budzinski H, Aliskandarani M. Optimization and comparisons for separation, detection and quantification of 12 aminoglycosides using 2 chromatographic conditions by LC-MS/MS. Am J Anal Chem. 2014;5(14):982994.

Mughal U-U-R, Dayo, A, Ghoto MA, Lal M, Arain MI, Parveen R, Gilal RA. Quantitative determination of amikacin sulfate using vanillin from pure and commercial brands available in Pakistan. J Young Pharm.2016;8(1):28-32.

Nanda RK, Navathar DA, Kulkarni AA, Patil SS. Simultaneous spectrophotometric estimation of cefepime and tazobactam in pharmaceutical dosage form. Int J ChemTech Res. 2012;4(1):152-156.

Neelima K, Rajendra Prasad Y, Appalaraju N, Selena S, Nikhila R. Analytical method development and validation of cefepime hydrochloride and tazobactum sodium in bulk and sterile dry powder for injection by gradient RP-HPLC. Indo J Pharm Res. 2013;3(10):8400-8407.

Omar MA, Nagy DM, Hammad MA, Aly AA. Validated spectrophotometric methods for determination of certain aminoglycosides in pharmaceutical formulations. J Appl Pharm Sci. 2013;3(3):151-161.

OmaraaHA, Amin AS.New, simple and validated spectrophotometric method for determination of amikacin in biological samples and its pharmaceutical formulations, JPBSRD.2013;1(4)-1-11.

Panchal Vipul J, Desai Hemant T, Patel Nirav B, Panchal Kalpesh B. Development and validation of stability indicating method for simultaneous estimation of cefepime and tazobactam injection using RP-UPLC method. IOSR J Pharm. 2014;4(12):53-60.

Papanna RK, Krishnegowda JB, Nagaraja P. Spectrophotometric method determination of cefepime, Cefazolin sodium and Cefalothin in pure pharmaceutical dosage forms buy using ninhydrin. Int J Pharm PharmSci. 2015;7(5):194-199.

Patel A, Laxman P, Amit J, Mohammadali K, Sandip P. Simultaneous estimation of cefepime hydrochloride and sulbactam sodium in combined dosage form. J Chem Pharm Res.2015a;7(4):860-865.

Patel KA, Shah JS, Maheswari DG. A Review on analytical methods for determination of cephalosporins and oxazolidinones bulk and in different dosage forms. World J Pharm Pharm Sci. 2015b;4(11):595-611.
Patel PN, Patel UD, Bhavsar SK, Thaker AM.Pharmacokinetics of cefepime following intravenous and intramuscular administration in sheep. Int J Pharm Tech.2010;9(1):7-10.

Patil AJ, Bhavsar SK, Patel HB, Patel NN, Patel SD, Dewda S, Patel JH, Thaker AM.Effect of ketoprofen co-administration on pharmacokinetic of cefepime in cow calves.Inter J Vet Sci. 2012;1(2):72-75.

Pickering LK, Rutheford I. Effect of concentration and time upon inactivation of tobramycin, gentamicin, netilmicin and amikacin by azlocillin, carbenicillin, mecillinam, mezlocillin and piperacillin. J Pharmacol Exp Ther.1981;217(2):345-9.

Ramakrishna K, Gouthami K, Sunitha G, Venkat RAJ Y, Panikumar A. Quantification and stress degradation studies of cefepime/ tazobactam in dry injection form by an RP-HPLC method. Braz J Pharm Sci. 2014;50(4):895-901.

Rambabu C, Jyothirmayee CA, Naga Raju K. Spectrophotometric analytical study for the charge-transfer complex formation of cefepime. Int J Pharm Pharmac Sci. 2012;4(1):417-418.

Ryan JA. Colorimetric determination of gentamycin, kanamycin, tobramycin, and amikacin aminoglycosides with 2,4-di nitrofluorobenzene. Journal of Pharmaceutical Sciences. 1984;73(9):1301-1302.

Soltés L. Aminoglycoside antibiotics D two decades of their HPLC Bioanalysis. Biomed Chromatogr.1999;13(1):3-10.

Sujith M, Abraham S, Divakar MC. Visible spectrophotometric method for the estimation of cefepime. Hygeia J D Med. 2010;2(2):32-37.

Sunitha N, Sindhura L, Thangbalan B, Manohar Babu S. Development and validation of RP-HPLC method for simultaneous estimation of cefepime and tazobactam in injection formulation. Asian J Pharm Anal. 2013;3(4):131-137.

Syam Sundar B, Gurucharana Das V. Development and validation of RP-HPLC method for the estimation of fourth generation cephalosporins (cefepime) in pure and dosage form. J Chem Pharm Sci. 2014; Special Issue:64-67.

Tally FP, Louie TJ, Weinstein WM, Bartlett JG, Gorbach SL. Amikacin therapy for severe gram-negative sepsis, emphasis on infections with gentamicin-resistant organisms. Ann Intern Med. 1975;83(4):484-8. 
Stability indicating RP-HPLC method development and validation of cefepime and amikacin in pure and pharmaceutical dosage forms

Trivedi HK, Kshtri N, Patel MC. A rapid, validated RPHPLC method for the simultaneous determination of cleaning validation and cross-contamination of $12 \beta$-lactam compounds. Sci Pharm. 2013;81(1):151-165.
World Health Organization. WHO. WHO Model List of Essential Medicines.Geneva: Switzerland; October 2013. Retrieved 22 April 2014.

Received for publication on $21^{\text {st }}$ May 2017 Accepted for publication on $30^{\text {th }}$ January 2018 